\title{
Ephrin-B1 forward and reverse signaling are required during mouse development
}

\author{
Alice Davy, Josée Aubin, and Philippe Soriano ${ }^{1}$ \\ Program in Developmental Biology, Division of Basic Sciences, Fred Hutchinson Cancer Research Center, \\ Seattle, Washington 98109, USA
}

\begin{abstract}
Eph receptors and ephrin ligands are key players in many developmental processes including embryo patterning, angiogenesis, and axon guidance. $\mathrm{Eph} / \mathrm{ephrin}$ interactions lead to the generation of a bidirectional signal, in which both the Eph receptors and the ephrins activate downstream signaling cascades simultaneously. To understand the role of ephrin-B1 and the importance of ephrin-B1-induced reverse signaling during embryonic development, we have generated mouse lines carrying mutations in the $e$ fnb1 gene. Complete ablation of ephrin-B1 resulted in perinatal lethality associated with a range of phenotypes, including defects in neural crest cell (NCC)-derived tissues, incomplete body wall closure, and abnormal skeletal patterning. Conditional deletion of ephrin-B1 demonstrated that ephrin-B1 acts autonomously in NCCs, and controls their migration. Last, a mutation in the PDZ binding domain indicated that ephrin-B1-induced reverse signaling is required in NCCs. Our results demonstrate that ephrin-B1 acts both as a ligand and as a receptor in a tissue-specific manner during embryogenesis.
\end{abstract}

[Keywords: Ephrin; neural crest cells; PDZ domain; signaling]

Received November 24, 2003; revised version accepted January 28, 2004.

Receptor tyrosine kinases (RTKs) and their ligands are essential for cellular communication and integration of extracellular signals. As such, they are involved in many aspects of embryonic development, by regulating proliferation, differentiation, apoptosis, or migration. The Eph receptors and their ligands, the ephrins, constitute one such system by which cells are able to interpret environmental cues and participate in proper developmental processes. Although Eph receptors and ephrins are involved in several embryonic processes (Wilkinson 2001; Adams 2002; Palmer and Klein 2003), they seem to achieve many of their functions by controlling cell movement. Eph receptors and ephrins were first characterized for their role in the formation of retinotectal topography, axon pathfinding (for reviews, see Drescher 1997; Wilkinson 2001), and neural crest cell (NCC) migration (Krull et al. 1997; Smith et al. 1997; Wang and Anderson 1997). In early studies, the ephrins were proposed to act as repulsive cues for Eph expressing axons or cells. It was later recognized that ephrins, which are membrane-bound proteins, are able to transduce a signal following interaction with their cognate Eph receptor (Henkemeyer et al. 1996; Holland et al. 1996; Bruckner et al. 1997; Davy et al. 1999; Huai and Drescher 2001). The ephrin-induced signaling cascade is now referred to as "reverse" signaling, as opposed to the "forward" sig-

${ }^{1}$ Corresponding author.

E-MAIL psoriano@fhcrc.org; FAX (206) 667-6522.

Article and publication are at http://www.genesdev.org/cgi/doi/10.1101/ $\operatorname{gad} .1171704$ naling activated downstream of Eph receptors. Both forward and reverse signaling were shown to be required for cell repulsion in an animal cap assay in Xenopus laevis (Mellitzer et al. 1999).

Whereas type A ephrins are tethered to the membrane via a glycosylphosphatidyl inositol group, type B ephrins are transmembrane proteins. All three ephrinBs (B1, B2, and B3) possess a highly conserved cytoplasmic domain, of which the last 33 amino acids are $100 \%$ identical between all three proteins. This C-terminal stretch contains a number of signaling motifs, including tyrosines that can be phosphorylated in vitro (Holland et al. 1996; Bruckner et al. 1997) and in vivo (Kalo et al. 2001) and a PDZ-binding domain (Lin et al. 1999). Several studies have characterized reverse signaling in vitro and proposed that both tyrosine phosphorylation and binding of PDZ-containing proteins are required for the function of transmembrane ephrins. Tyrosine phosphorylation of the cytoplasmic tail of ephrin-B1 in response to Eph receptor binding has been proposed to be necessary for cell rounding and morphological changes, via a cascade involving recruitment of Grb4 to phosphorylated tyrosines (Cowan and Henkemeyer 2001). Others have indicated that Src-family kinases are involved in tyrosine phosphorylation of ephrin-B1 and that this phosphorylation event is necessary for inducing sprouting angiogenesis following activation of ephrin-B1 in endothelial cells (Palmer et al. 2002). Several PDZ-containing proteins have been shown to bind to transmembrane ephrins (Torres et al. 1998; Lin et al. 1999); however, the significance of some of these interactions for the function of 
Ephrin-B1 signaling in mouse development

transmembrane ephrins remains unclear. It has been shown more recently that PDZ-RGS3, a PDZ domaincontaining protein that is a regulator of G-protein signaling, is an important effector of ephrin-B1-induced reverse signaling that selectively inhibits G-protein coupled chemoattraction of cerebellar granule cells (Lu et al. 2001).

In vivo, the importance of reverse signaling has only been assessed by deleting the entire cytoplasmic domain of ephrin-B2 or ephrin-B3 (Mellitzer et al. 1999; Adams et al. 2001; Yokoyama et al. 2001). For instance in the mouse, evidence that reverse signaling activated by transmembrane ephrins is important during embryonic development was provided by the demonstration that a mutated ephrin-B2 lacking the entire cytoplasmic tail was unable to rescue the vascular defects associated with the complete loss of ephrin-B2 (Adams et al. 2001). Although very effective at evaluating the importance of the cytoplasmic domain of transmembrane ephrins for their function, the deletion of such a significant portion of the protein could have drastic effects either on subcellular localization or recycling. It has been shown recently that bidirectional trans-endocytosis of Eph receptors/ephrins complexes is required for efficient cell repulsion and that deletion of the cytoplasmic domain of ephrin-B1 blocks its endocytosis and therefore impairs contact-mediated repulsion (Zimmer et al. 2003). This process, which is independent of either tyrosine phosphorylation or binding of PDZ-containing proteins, could account for the phenotype observed in mutants expressing such truncated forms of transmembrane ephrins. In addition, contribution of individual signaling cascades to the reverse signaling could not be assessed in this type of study.

Ephrin-B1 was the first member of the B-class ephrins to be cloned. It was initially identified as an Eph receptor-binding protein (Fletcher et al. 1994) and as a retinoic acid (RA)-responsive gene (Bouillet et al. 1995). It is expressed broadly, albeit not ubiquitously, during embryogenesis, and its expression decreases in the adult, suggesting that ephrin-B1 might play an important role during embryonic development. To characterize the role of ephrin-B1 during embryonic development, and to evaluate the importance of reverse signaling for the function of ephrin-B1 in vivo, we have generated a conditional null mutation of the efnb1 gene. In parallel, we have engineered a mouse line carrying a mutated form of ephrin-B1, in which the PDZ-binding domain was impaired. During the course of this work, it was shown that ephrin-B1 is involved in skeletal patterning during mouse embryogenesis (Compagni et al. 2003). In agreement with this report, we show that ephrin-B1-deficient animals present skeletal defects. We have focused our analysis on the limb bud defect and used marker analysis to understand the role of ephrin-B1 in digit formation. In addition, we now demonstrate that ephrin-B1 acts cell autonomously in NCC to regulate craniofacial development. Last, we show that the PDZ-binding domain is required for proper development of NCC-derived structures, indicating that ephrin-B1-induced reverse signaling is required in a tissue-specific manner during embryogenesis.

\section{Results}

Ephrin-B1 is required for embryonic development

To study the role of ephrin-B1 in development, we generated two independent lines of mice deficient for ephrin-B1 by conditionally deleting the entire coding region of the gene (Fig. 1A). Ephrin-B1 conditional mutants (ephrin-B $1^{\text {lox }}$ ) were recovered with the expected Mendelian ratio in both a mixed 129S4/C57B16J background and a congenic 129S4 background. Deletion of the Xlinked efnb1 gene was accomplished by crossing the ephrin-B1 ${ }^{\text {lox }}$ animals with animals expressing the Cre recombinase under the control of the Meox2 promoter (Fig. 1A; Tallquist and Soriano 2000). Proper recombination of the locus was assessed by Southern blot and revealed that in the first generation, recombination of the efnb1 locus in mice carrying the Meox2-Cre allele was mosaic (Fig. 1B, panel a). In the following generation, deletion of the efnb1 gene was complete (Fig. 1B, panels b,c). Absence of the ephrin-B1 protein in the ephrin-B1 null (ephrin-B $1^{\text {null }}$ ) animals was confirmed by Western blot on embryo lysates (Fig. 1C).

At 2 wk of age, ephrin-B1-deficient animals were not recovered with the expected Mendelian ratio, suggesting that loss of ephrin-B1 is associated with early lethality (Table 1). Interestingly, both the hemizygous males, which express no ephrin-B1, and the heterozygous females, which still express a half-dose of ephrin-B1, showed the perinatal lethality phenotype (Table 1). Because ephrin-B1 is X-linked, its expression in heterozygous females is necessarily mosaic. Because of random $\mathrm{X}$-inactivation, half of the cells will express ephrin-B1 in heterozygous females, and the other half will be deficient for ephrin-B1. Our results indicate that expression of ephrin-B1 in only half of the cells is not enough to achieve normal development. This underrepresentation of ephrin-B1-deficient animals was observed both in the mixed background and in the 129S4 congenic background, but the penetrance of the lethal phenotype was higher in the latter. Most of the analysis presented here was done on the mixed background, because ephrin-B1deficient animals could be recovered more easily.

Ephrin-B1-deficient animals were recovered at the expected Mendelian ratio at embryonic day 18.5 (E18.5; data not shown), suggesting that loss of ephrin-B1 was associated with perinatal lethality. Indeed, many of the ephrin-B1-deficient animals were found dead at postnatal day 1 (P1). Approximately $70 \%$ of the ephrin-B1-deficient animals presented developmental defects that could account for the lethality such as cleft palate and body wall closure defect. Skeleton preparations also revealed that a significant number of animals exhibited abnormal sternum and rib development (data not shown).

\section{Ephrin-B1-dependent sorting-out mechanism in heterozygous females leads to polydactyly}

Not only did the ephrin-B1 heterozygous females exhibit the same perinatal lethality phenotype as the null animals, but they also exhibited polydactyly. This pheno- 
Davy et al.

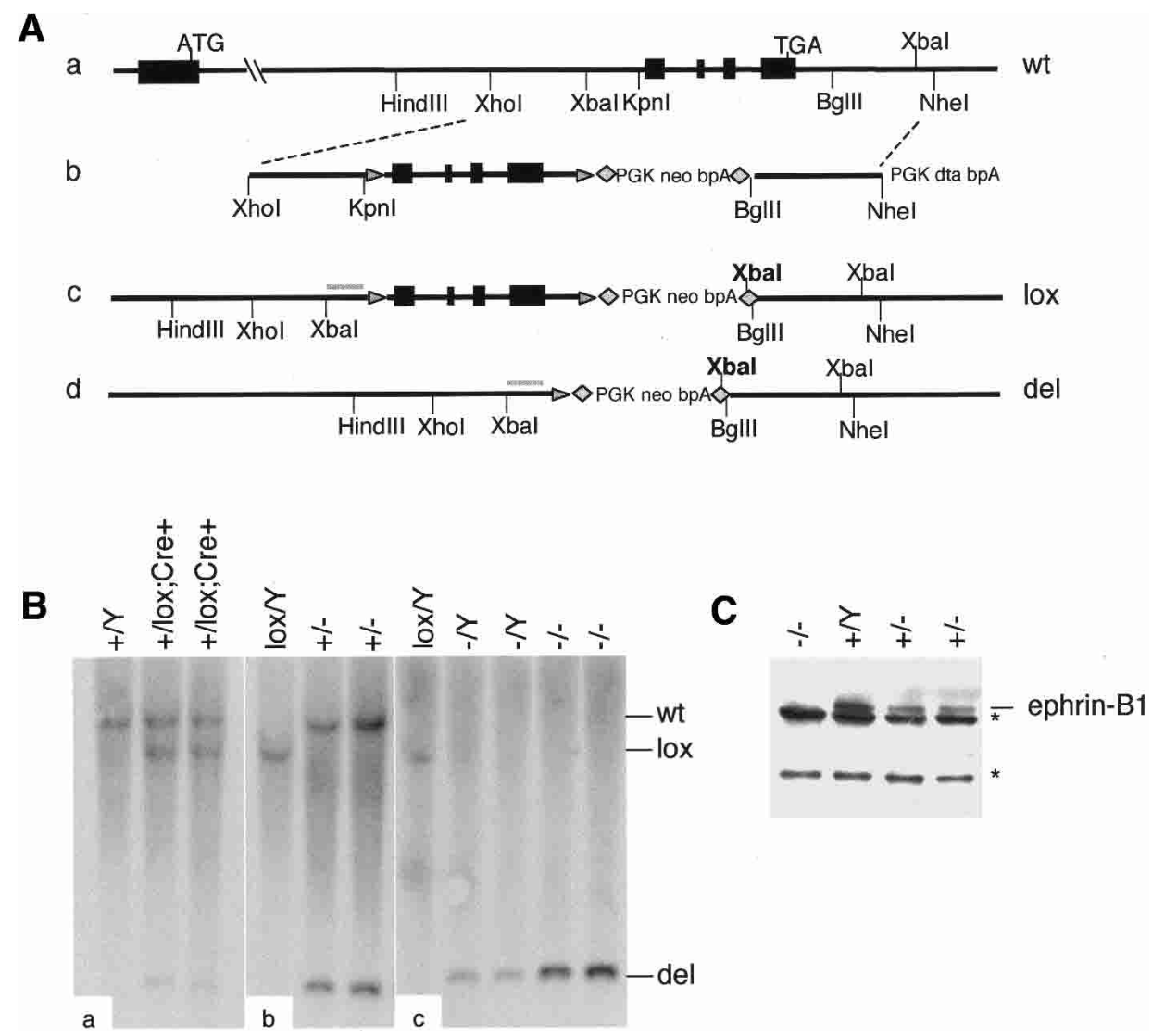

Figure 1. Targeting of the efnb1 locus. (A) Wild-type efnb1 locus (panel a) was targeted by homologous recombination of a targeting vector (panel $b$ ) carrying exons 2-5 of efnb1 gene flanked by loxP sites (triangles) and a positive selection cassette flanked by FRT sites (diamonds). The conditional allele (lox; panel $c$ ) is recombined in the presence of the Cre recombinase, producing a null allele (del; panel $d) .(B)$ Tail DNA from P10 pups was analyzed by Southern blot analysis in order to confirm proper targeting and recombination in the presence of the Cre recombinase (XbaI digest with a probe indicated in gray in panels $c$ and $d$ ). Restriction digests of DNA from first-generation pups (panel $a$ ) as well as second-generation pups (panels $b, c$ ) are presented. $(C)$ Western blot analysis showing loss of ephrin-B1 at the protein level in homozygous null E10.5 embryos $(-/-)$, and decreased levels of ephrin-B1 in heterozygous embryos $(+/-)$, as compared with wild-type $(\mathrm{Y} /+)$ littermates. Nonspecific bands are indicated (asterisks).

type was observed with a $100 \%$ penetrance in ephrin-B1 heterozygous females (Fig. 2A, panel b) but not in hemizygous ephrin-B $1^{\text {null }}$ males (Fig. 2A, panel a) or homozygous ephrin-B1 ${ }^{\text {null }}$ females (data not shown). The polydactyly was almost always restricted to digits I or II, either in forelimbs or hindlimbs. Although this phenotype was observed in both mixed and congenic backgrounds, in the 129S4 background the defects affected only the last phalange (data not shown). In situ hybrid- ization revealed that ephrin-B1 expression in E11.5 limb buds of heterozygous females was strikingly different than in the wild-type littermate, with alternating rays of ephrin-B1-positive and ephrin-B1-negative cells (Fig. 2B, panels $\mathrm{a}, \mathrm{b})$. No expression was detected in null embryos (Fig. 2B, panel c). This atypical expression pattern cannot solely reflect random $\mathrm{X}$-inactivation, because this process occurs earlier in development and should give rise to a much finer distribution of ephrin-B1-positive and

Table 1. Impaired viability of ephrin-B1-deficient animals

\begin{tabular}{|c|c|c|c|c|c|c|}
\hline & & $1^{\mathrm{Y} / \mathrm{lox}} ; \mathrm{Meo}$ & & & 31 $1^{+/ l o x} ;$ Meor & \\
\hline & Expected & Recovered & $\%$ & Expected & Recovered & $\%$ \\
\hline Mixed background & 13.75 & 8 & 58 & 13.75 & 1 & 7.2 \\
\hline 129 background & 10.3 & 2 & 19.4 & 10.3 & 2 & 19.4 \\
\hline
\end{tabular}

Number of mutants recovered from crosses between conditional ephrin-B1 animals and animals carrying one copy of the Cre recombinase expressed under the control of the Meox 2 promoter (ephrin-B $1^{\text {lox } /+} ;$ Meox $2^{+/+} \times$ephrin-B $1^{\mathrm{Y} /+} ;$ Meox $2^{\text {Cre/+ }}$ ). \% indicates viability of ephrin-B1 deficient animals. 
negative cells. Instead, the size and distribution of the ephrin-B1-positive patches were suggestive of a sortingout mechanism in heterozygous females, in which ephrin-B1-positive cells are segregated away from ephrin-B1negative territories. In support of this hypothesis, ephrin-B1 was uniformly expressed in E8.5 heterozygous embryos (data not shown), indicating that this sorting out is an active process that occurs over time.

Expression of one member of the Eph receptor family, EphA4, has been shown to be altered in the polydactylous talpid ${ }^{3}$ mutant in the chick (Patel et al. 1996). To test whether expression of EphA4 was also affected in ephrin-B1 heterozygous females, we analyzed E12.5 limb buds for EphA4 expression by whole-mount immunohistochemistry. The alteration in ephrin-B1 expression pattern correlated with a change in the expression pattern of EphA4 receptor. In a wild-type limb bud, EphA4 was expressed throughout the mesenchyme below the apical

A
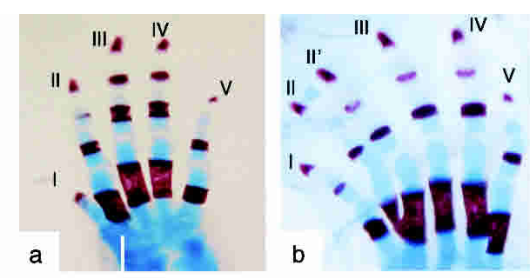

B

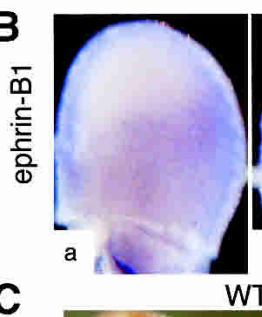

C
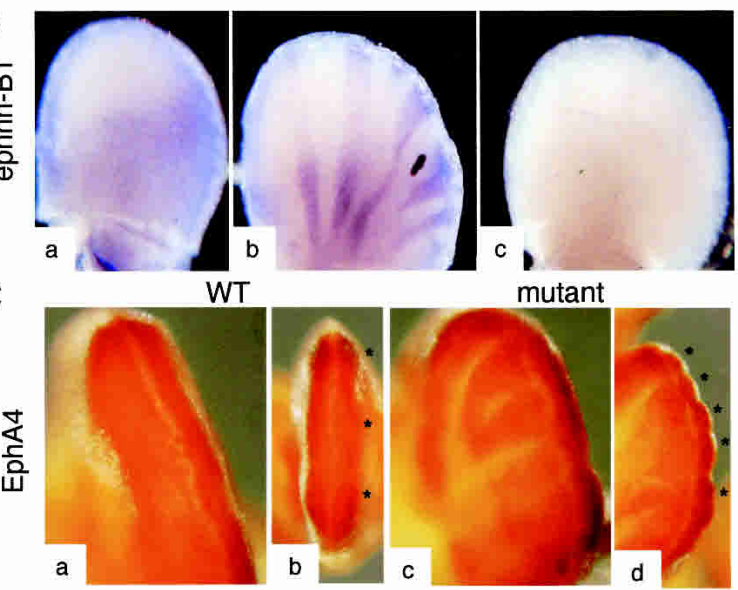

T
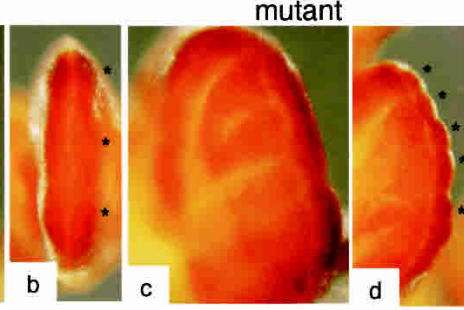

D

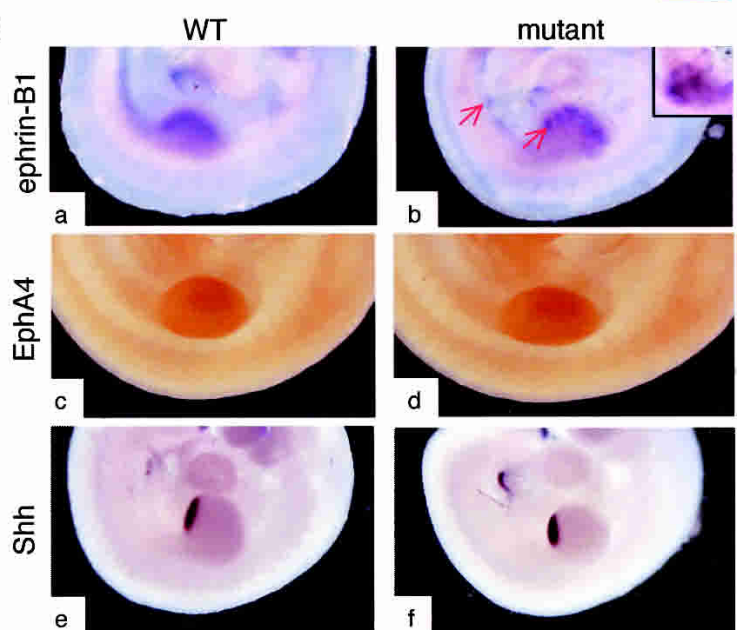

ectodermal ridge (AER) (Fig. 2C, panel a), but was slightly enriched around sites of mesenchymal condensations (Fig. 2C, panel b). In ephrin-B1 heterozygous limb buds, the distribution of EphA4 was reminiscent of that of ephrin-B1, with the appearance of stripes of EphA4positive cells (Fig. 2C, panel c). Strikingly, EphA4-positive stripes labeled bulging areas in the limb bud that could potentially be ectopic sites of mesenchymal condensation (Fig. 2C, panel d). In the chick mutant talpid ${ }^{3}$, ectopic EphA4 expression can be detected before mesenchymal condensation begins. To test whether altered Eph4 expression could also be detected before mesenchymal condensation takes place in ephrin-B1 heterozygous mutants, we analyzed embryos at earlier stages of development. In E10.5 heterozygotes, ephrin-B1-positive cells were not yet organized in stripes, although expression of ephrin-B1 was already very patchy in the limb buds and in other tissues (Fig. 2D, panels a,b). Expression of EphA4, on the contrary, was homogenous (Fig. 2D, panels c,d), indicating that ephrin-B1 does not directly regulate the expression of EphA4 or the distribution of EphA4-positive cells at that stage and that deregulation of EphA4 is probably not causal for the polydactyly phenotype. At E12.5, misexpression of EphA4 in ephrin-B1 heterozygous limb buds correlates with the presence of more numerous mesenchymal condensations. Alteration of Sonic hedgehog (Shh) expression is often associated with polydactyly (Hill et al. 2003); however, expression of Shh in the limb buds was identical in wild-type embryos and ephrin-B1 heterozygous embryos (Fig. 2D, panels e,f). Similarly, Hoxa13, which is involved in patterning of the digits (Zakani and Duboule 1999) did not present an altered expression pattern in heterozygous limb buds at E10.5 (data not shown).

Figure 2. Altered expression of ephrin-B1 in heterozygous females correlates with polydactyly. (A) Skeletal preparations from an ephrin-B1 null male (panel $a$ ) and a heterozygous female (panel $b$ ) were stained with Alcian blue and Alizarin red. Polydactyly, affecting digit II, is observed in the heterozygous females but not the null male. $(B)$ In situ hybridization of E11.5 limb buds shows an altered ephrin-B1 expression pattern in heterozygous limb buds (panel $b$ ) as compared with wild-type limb bud (panel $a$ ). (Panel $c$ ) No expression is detected in a null limb bud. $(C)$ EphA4 expression pattern, detected by immunohistochemistry, is perturbed in heterozygous limb buds. Wild-type limb buds present a homogenous EphA4 expression (panel $a$ ) and three distinct areas of condensation can be seen (asterisks), corresponding to the prospective digits II, III, and IV (panel $b$ ). In ephrin-B1 heterozygous limb buds, EphA4 is distributed in multiple stripes (panel $c$ ) and multiple areas of condensation are observed (asterisks, panel $d$ ). Panels $a, b, c$, and $d$ are different views of the same limb bud. $(D)$ In situ hybridization of E10.5 wild-type (panels $a, c, e$ ) and heterozygous mutant (panels $b, d, f$ ) embryos. Expression of ephrin-B1 is patchy in the heterozygous mutants (panel $b$ ), with ephrin-B1-positive cells (red arrows) sorting out from ephrin-B1-negative territories. (Panel $d$ ) Insert is a different heterozygous limb bud. (Panel f) EphA4 distribution is unchanged in the mutant embryos. No ectopic Shh expression is detected in the mutant limb buds. 
To understand how ephrin-B1 could affect mesenchymal condensation, we cultured limb bud cells from wildtype and ephrin-B1 ${ }^{\text {null }}$ animals in high-density micromass assays. No difference in chondrogenic capacity was observed between wild-type and ephrin-B1 ${ }^{\text {null }}$ cells, as assessed by collagen II staining (Fig. 3A, panels a-f; data not shown). However, the chondrogenic micromasses seemed less well organized in the cultures obtained from the mutant cells. In particular, some individual collagen II positive cells tended to migrate away (Fig. 3A, panel e). Both ephrin-B1 and EphA4 were expressed in overlapping domains in the mesenchyme surrounding the chondrocytic micromasses, including in the perichondrium, sug-
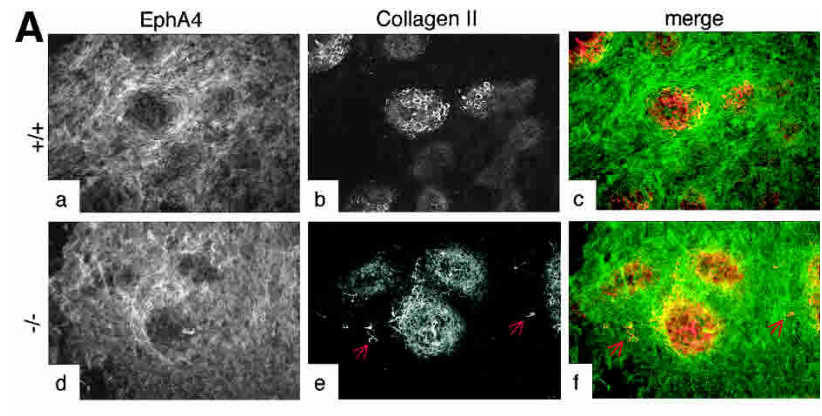

B EphA4
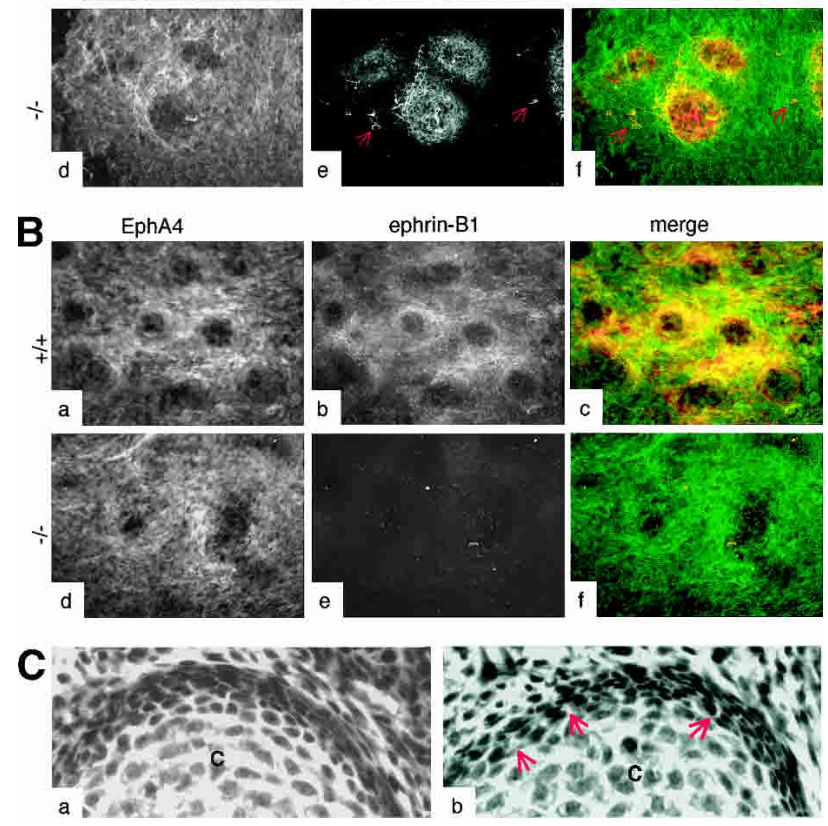

Figure 3. Loss of ephrin-B1 does not affect the chondrogenic capacity of limb bud cells in vitro. (A) High-density micromass cultures from limb bud cells isolated from wild-type (panels $a-c$ ) or ephrin-B1 null (panels $d-f$ ) E11.5 embryos were analyzed by immunofluorescence using the EphA4 antibody (green) and a collagen II-specific antibody (red), as indicated. Collagen II-positive cells (red arrows) can be detected outside the chondrogenic micromasses in the culture isolated from mutant embryos. $(B)$ High-density micromass cultures from limb bud cells isolated from wild-type (panels $a-c$ ) or ephrin-B1 null (panels $d-f$ ) E11.5 embryos were analyzed by immunofluorescence using the EphA4 antibody (green) and a monoclonal antibody specific for ephrin-B1 (25H11; red). Both EphA4 and ephrin-B1 are expressed in the cells surrounding the chondrogenic micromasses, including the perichondrium. $(C) \mathrm{H} \& \mathrm{E}$ staining of sections from wildtype (panel $a$ ) or ephrin-B1 heterozygous (panel b) E15.5 embryos. Space between cells can clearly be seen in mutant (arrows) but not in wild-type perichondrium. (Panel $c$ ) Chondrocytes. gesting that both proteins might be involved in defining the regions of cartilage differentiation (Fig. 3B, panels $\mathrm{a}-\mathrm{f})$. In vivo, the perichondrium around forming digits also appeared poorly organized in ephrin-B1 heterozygotes. Histological examination of developing digits indicated that although the perichondrium is clearly forming in ephrin-B1 heterozygotes, the cells are not as tightly associated in the mutant tissue (Fig. 3C, panel b) as compared with a wild-type control (Fig. 3C, panel a).

Taken together, these results indicate mosaic loss of ephrin-B1 results in a polydactyly phenotype in a Shhand Hoxa13-independent manner and suggest that ephrin-B1 plays a role in later stages of digit formation, possibly involving perichondrium formation or maintenance.

Ephrin-B1 acts cell autonomously in neural crest cells to regulate craniofacial development

The relatively high penetrance $(50 \%)$ of a cleft palate in ephrin-B1-deficient animals and the reported expression of ephrin-B1 at the edges of the palatal shelves /Orioli et al. 1996) prompted us to examine the role of ephrin-B1 in NCCs, because palatal shelves are derived from these cells. As a first step, we tested whether ephrin-B1 is expressed in NCCs. Immunofluorescence experiments indicated that ephrin-B1 was indeed expressed in primary cells isolated from branchial arches, which are primarily composed of NCCs (Fig. 4A, panels a,b). Ephrin-B1 could also be detected in branchial arches and migrating NCCs by in situ hybridization (data not shown). Interestingly, ephrin-B1 cognate receptors, detected through binding of an ephrin-B1-Fc chimeric protein, were also detected (Fig. 4A, panel b). Because both ephrin-B1 and its receptors are expressed in NCCs, ephrin-B1 could act nonautonomously on these cells by activating forward signaling, or ephrin-B1 could act cell autonomously in NCCs to regulate palate formation. To distinguish between these two possibilities, we deleted ephrin-B1 specifically in NCCs by crossing conditional ephrin-B1 ${ }^{\text {lox }}$ animals with transgenic mice that express the Cre recombinase under the control of the Wnt1 promoter (Danielian et al. 1998). These experiments revealed that a number of mutant animals in which ephrin-B1 was deleted only in the NCCs (ephrin-B1 ${ }^{\text {NCC }}$ ) exhibited a cleft palate (Fig. 4B, panels a-c). In addition, these mutants also exhibited defects in other NCC-derived tissues, such as the tympanic ring of the middle ear, which were also observed in the ephrin-B1 ${ }^{\text {null }}$ mutants (Fig. 4B, panels d-f). These results indicate that ephrin-B1 is required cell autonomously in NCCs.

The penetrance of the cleft palate in ephrin-B1 ${ }^{\mathrm{NCC}}$ mutants was lower than that observed for ephrin-B $1^{\text {null }}$ mutants ( $15 \%$ vs. $50 \%$ of the mutants, respectively). Histological examination of ephrin-B1 ${ }^{\text {null }}$ embryos revealed that the palatal shelves were missing entirely as early as E13.5 (Fig. 4C, panel b). On the contrary, palatal shelf development in ephrin-B1 ${ }^{\text {NCC }}$ embryos was identical to wild-type controls at this stage (Fig. 4C, panel c). It was only by E14.5, when the palatal shelves start to el- 
A
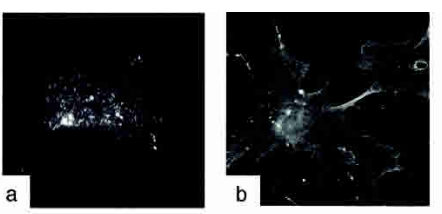

B

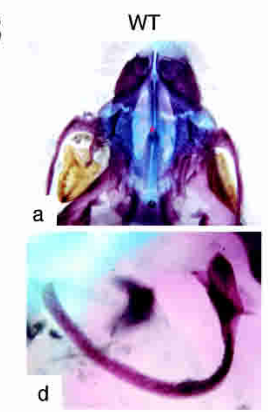

WT

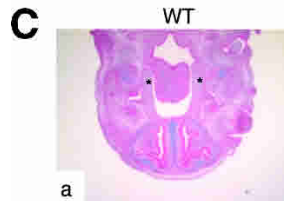

a
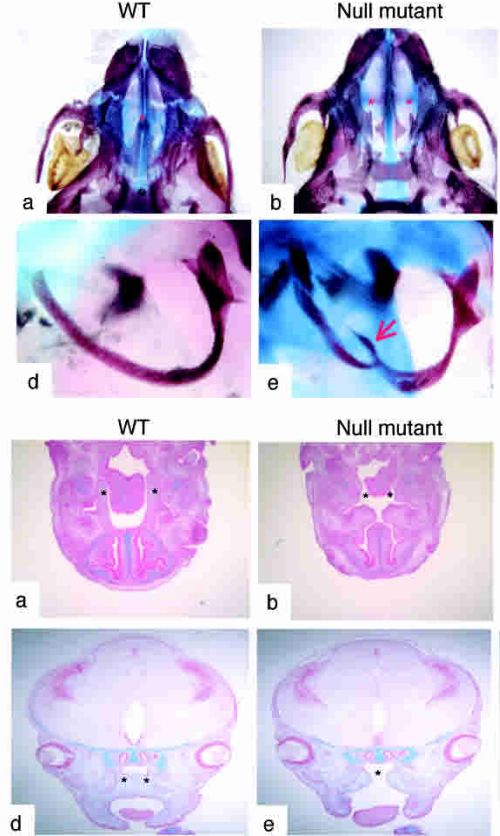

Null mutant
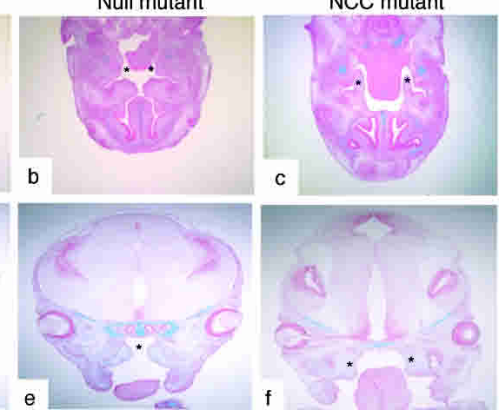

Figure 4. Ephrin-B1 acts autonomously in neural crest cells. (A) Primary cells isolated from branchial arches of E10.5 wildtype embryos were passaged once and analyzed by immunofluorescence using the ephrin-B1-specific antibody (25H11; panel $a$ ) or the ephrin-B1-Fc recombinant protein to detect EphB receptors (panel $b)$. $(B)$ Alcian blue/Alizarin red-stained skeleton preparations of wild-type (panels $a, d)$, ephrin-B1 ${ }^{\text {null }}$ (panels $b, e$ ), or ephrin-B1 ${ }^{\text {NCC }}$ (panels $c, f$ ). Palatal shelves (asterisks) are fused in the wild-type animal (panel $a$ ), but remain separated in ephrin-B1 $1^{\text {null }}($ panel $b)$ and in ephrin-B1 ${ }^{\text {NCC }}$ (panel $c$ ). Tympanic rings are defective bilaterally in ephrin-B1 ${ }^{\text {null }}$ (panel $e$ ) and in ephrin-B1 $^{\text {NCC }}$ (panel $f$ ). (C) Histological sections of wild-type (panels $a, d$ ), ephrin-B1 ${ }^{\text {null }}$ (panels $b, e$ ), or ephrin-B1 ${ }^{\text {NCC }}$ (panels $c, f)$, stained with Alcian blue and Nuclear Fast red. (Panels $a-c$ ) At E13.5, palatal shelves (asterisks) can be observed on transverse sections on each side of the tongue of wild-type (panel $a$ ) and NCC-deleted ephrin-B1 mutant (panel $c$ ). (Panel $b$ ) Embryowide deletion of ephrin-B1 precludes formation of palatal shelves. (Panels $d, e$ ) At E15.5, palatal shelves have elevated and fused (asterisks) in wild-type embryos (panel $d$ ). (Panel $e$ ) In ephrin-B1 $1^{\text {null }}$ embryos, the roof of the mouth has elevated but no palatal shelves are present. (Panel f) At E14.5, palatal shelves (asterisks) are formed in ephrin-B1 ${ }^{\mathrm{NCC}}$ mutants, but they failed to elevate.

evate, that the defect in ephrin-B1 ${ }^{\mathrm{NCC}}$ mutants became apparent (Fig. 4C, panel f). These results indicate that ephrin-B1 may be required both cell autonomously and nonautonomously in NCCs to regulate craniofacial development.

To obtain a better understanding of the role of ephrinB1 in NCC-derived tissues, we examined proliferation and apoptosis, using an antibody to phospho-HistoneH3 and TUNEL labeling, respectively, but no alterations were found in the mutant animals as compared with wild-type littermates (data not shown). To track populations of NCCs in more detail, we labeled NCC specifically by using the R26R allele. This allele, which restricts $\beta$ galactosidase expression to cells where Cre recombinase is expressed and labels the progeny of such cells (Soriano 1999), was introduced in ephrin-B1 ${ }^{\text {NCC }}$ and ephrin-B $1^{\text {null }}$ animals in combination with the Wnt1-Cre transgene, thus allowing expression of $\beta$ galactosidase in NCCs. Whole-mount X-gal staining of E9.5 embryos revealed discrete areas of altered staining pattern in ephrin-B1 ${ }^{\text {null }}$ and ephrin-B1 ${ }^{\text {NCC }}$ mutant embryos, suggestive of directional migration defects. Mutant NCCs migrating from postotic rhombomeres toward branchial arches 3 and 4 seemed to exhibit a wandering behavior as compared with the stereotypical migration path followed by the wild-type cells (Fig. 5A). As a consequence, mutant NCCs were invading territories that are normally devoid of crest cells. Both cranial and cardiac NCCs were affected, whereas no major migration defects were observed in trunk NCCs. Formation of cranial ganglia, which are derived from NCCs, was analyzed by whole-

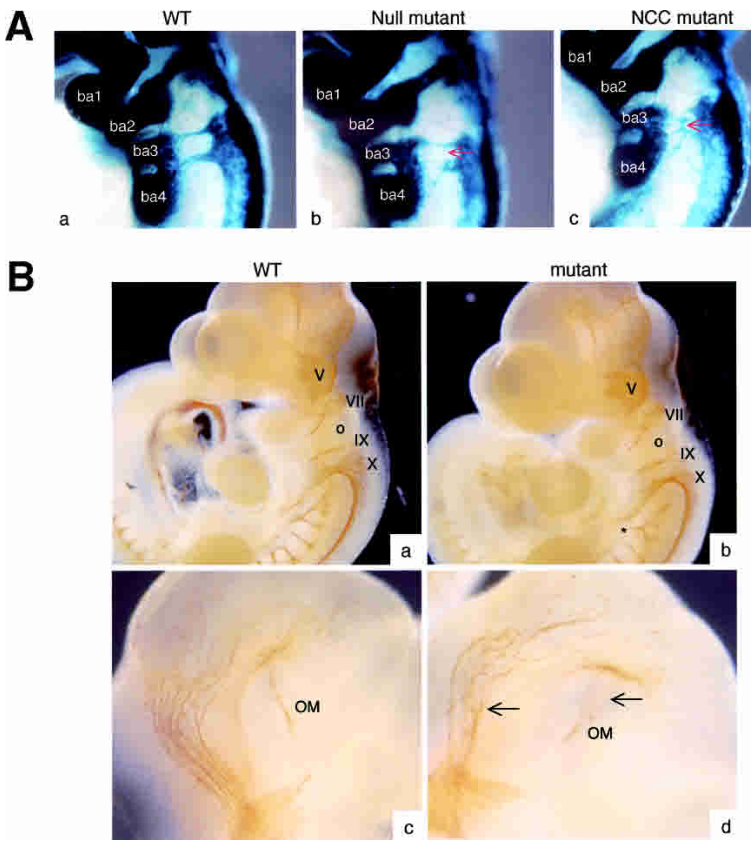

Figure 5. Loss of ephrin-B1 induces NCC migration defects. (A) Whole-mount X-gal staining of E9.5 wild-type (panel $a$ ), ephrin-B1 ${ }^{\text {null }}$ (panel $b$ ), or ephrin-B1 ${ }^{\mathrm{NCC}}$ (panel $c$ ). Mutant NCC exhibit a wandering behavior in ephrin-B1 ${ }^{\text {null }}$ (panel $b$ ) and ephrin$\mathrm{B} 1^{\mathrm{NCC}}$ embryos (panel $c$ ), as compared with wild-type (panel $a$ ). Mutant cells invade territories that are normally devoid of crest cells (red arrows). (B) Whole-mount immunohistochemistry staining of E10.5 wild-type (panels $a, c$ ) and ephrin-B1 ${ }^{\text {null }}$ (panels $b, d)$ embryos using a neurofilament antibody. Cranial ganglia V-X appear normal in the mutant embryos, but branching (asterisk) and fasciculation (arrow) defects can be observed. (ba) Branchial arches; (o) otic vesicle; (OM) occulomotor nerve. 
Davy et al.

mount immunohistochemistry using an anti-neurofilament antibody. In E10.5 ephrin-B1 ${ }^{\text {null }}$ mutant embryos, all cranial ganglia were developing normally. These experiments revealed, however, fasciculation and branching defects in both NCC-derived and non-NCC-derived nerve in the mutant embryos (Fig. 5B; data not shown). In particular, the occulomotor nerve was affected in $100 \%$ of the mutants analyzed $(n=8$; Fig. $5 B$, panel $d)$. The role of ephrin-B1 in these processes awaits further analysis.

Loss of the transcription factor Twist has been shown to affect NCC migration, with Twist-deficient NCCs invading territories that are normally devoid of crest cells (Soo et al. 2002). To test whether expression of Twist was perturbed in ephrin-B1 mutant animals, we performed in situ hybridization experiments that indicated that expression of Twist was not disrupted in ephrinB1 ${ }^{\text {null }}$ embryos. Similarly, expression of Sox9, which is involved in cranial neural crest development and craniofacial development (Spokony et al. 2002; Mori-Akiyama et al. 2003), was not affected in ephrin-B1 ${ }^{\text {null }}$ mutants (data not shown).

Taken together, these results indicate that ephrin-B1 is required autonomously in NCCs for proper migration of these cells. Neural crest migration defects do not impair formation and differentiation of cranial ganglia. However, loss of ephrin-B1 results in fasciculation and branching defects in specific neuronal populations.

\section{Ephrin-B1-induced reverse signaling is required for embryonic development}

To test the importance of reverse signaling for the function of ephrin-B1 during embryonic development, we generated a mutant form of ephrin-B1 in which the PDZ binding domain was impaired (ephrin-B1 ${ }^{\Delta \mathrm{PDZ}}$ ). The mutation was generated by removing the valine at the $\mathrm{C}$ terminus of the ephrin-B1 protein, which had been shown previously to weaken binding of PDZ-containing proteins (Lu et al. 2001). We tested the mutation using cotransfection experiments in $293 \mathrm{~T}$ cells. Wild-type or mutant ephrin cDNAs were coexpressed with a flagtagged PDZ domain (see Materials and Methods) and pull-down assays revealed that the $\triangle \mathrm{PDZ}$ mutant exhibited a $75 \%$ reduction in its capacity to bind PDZ-flag (Fig. 6A). Importantly, binding of the PDZ-flag was not impaired in a control mutant in which tyrosines were mutated to phenylalanine (P-Tyr; Fig. 6A). Ephrin-
Figure 6. Generation of ephrin-B1 $1^{\Delta \mathrm{PDZ}}$ mutant. $(A)$ Wild-type ephrin cDNA (WT), or mutant cDNA ( $\triangle \mathrm{PDZ}$ and P-tyr) were transfected into $293 \mathrm{~T}$ cells together with a flag-tagged PDZ domain. The EphB2-Fc recombinant protein was used to pull down ephrin and the amount of PDZ domain coimmunoprecipitated was evaluated with an anti-flag antibody. The right panel shows a quantification of the amount of PDZ domain associating with wild-type and mutant ephrin. The asterisk indicates a nonspecific band. $(B$, panel $a)$ Wildtype efnb1 locus. (Panel $b$ ) Homologous recombination of the vector for the $\triangle \mathrm{PDZ}$ mutation introduces a HindIII site. $(C$, panel $a$ ) Southern blot analysis of targeted $\triangle$ PDZ ES cells. Genomic DNA was digested with Hin$\mathrm{dIII}$ and the probe used is indicated in gray in panel $b$ of part $B$. Genomic DNA from different ES clones was used as a template for PCR (panel $b$ ), using either mutation-specific primers (top) or primers specific to exon 5 (bottom). (D) ES cells treated with retinoic acid (RA) were analyzed by Western blot using the ephrin antibody (C18). Ephrin-B1 could be detected in wild-type ES cells (WT), ES cells targeted with the conditional allele of ephrin-B1 (lox), and ES cells targeted with $\triangle \mathrm{PDZ}$ mutation ( $\triangle \mathrm{PDZ})$. To ascertain that the signal was specific for ephrin-B1, we also tested ES cells deficient for ephrin-B1 (null). These cells were obtained by transiently expressing the Cre recombinase in ephrin-B1 ${ }^{1 \text { ox }}$ ES cells and screening for recombined clones. The asterisks indicate nonspecific bands. (E) Embryos obtained by injection of ES cells carrying the ephrin-B1 $1^{\triangle \mathrm{PDZ}}$ mutation into ROSA26 blastocysts were stained with X-gal to evaluate the degree of contribution of the mutant ES cells. Two different tissues (spinal chord, top and limb bud, bottom) from four different E14.5 embryos are presented (ch1-ch4). The embryos with the most contribution of the mutant ES cells (ch3 and ch4) presented a cleft palate $(+)$, whereas the embryos with very little contribution of the mutant ES cells (ch1 and ch2) did not have a cleft palate (-). (F) Histological examination of E14.5 embryos obtained by injection of ES cells carrying the ephrin$\mathrm{B} 1^{\mathrm{PDZ}}$ mutation into wild-type blastocysts. (Panels $\left.b, d\right)$ Palatal shelves (asterisks) were formed but failed to elevate and fuse in the chimeric embryo. (Panels $a, c$ ) Littermate without a cleft palate. Sections were stained with Alcian blue and Nuclear Fast red.
A
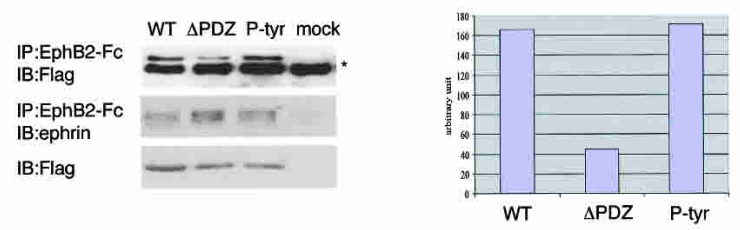

B
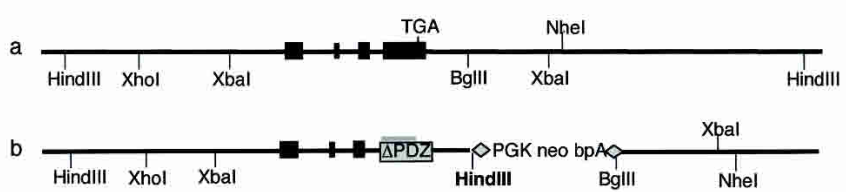

C

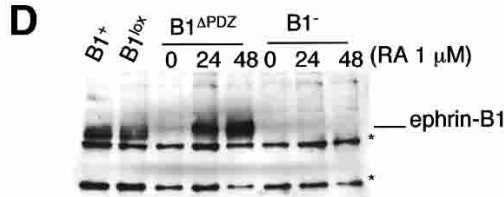

E

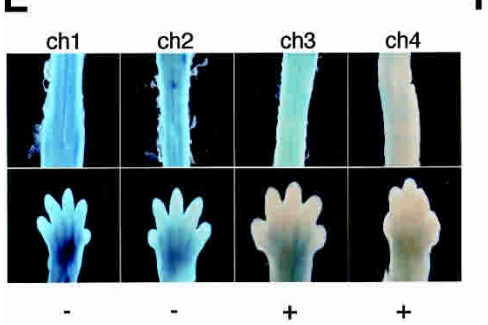

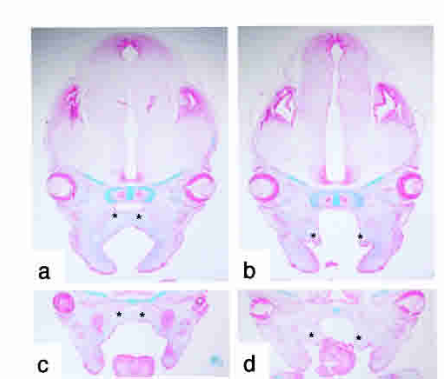


$\mathrm{B} 1^{\triangle \mathrm{PDZ}}$ was introduced in ES cells by homologous recombination of the appropriate targeting vector (Fig. 6B, panel b). Southern blotting confirmed that two clones of ES cells were properly targeted (Fig. 6C, panel a) and the presence of the mutation in both clones was ascertained by PCR using primers specific for the mutation (Fig. 6C, panel b). Because the ES cells were derived from an XY blastocyst, they contain only one allele of efnb1. Thus, following targeting, only ephrin-B1 ${ }^{\Delta \mathrm{PDZ}}$ will be expressed in these cells. To verify that targeting had not perturbed $e f n b 1$ expression, and that ephrin-B1 ${ }^{\Delta \mathrm{PDZ}}$ was stable, we treated targeted ES cells with RA, because efnb1 has been shown to be an RA-inducible gene (Bouillet et al. 1995). Following this treatment, ephrin-B1 ${ }^{\Delta \mathrm{PDZ}}$ could be detected in targeted ES cells at similar levels as wild-type ephrin-B1 (Fig. 6D). No signal was detected in ES cells in which ephrin-B1 was deleted.

Only two female chimeras exhibiting a low degree of chimerism were recovered following multiple injections of both ES clones into blastocysts, suggesting that the viability of the chimeric embryos is impaired. This observation prompted us to examine the ephrin-B1 ${ }^{\Delta \mathrm{PDZ}}$ chimeras during embryonic development. ES clones carrying ephrin-B1 ${ }^{\triangle \mathrm{PDZ}}$ mutation were injected into ROSA 26 blastocysts that express $\beta$ galactosidase ubiquitously (Zambrowicz et al. 1997). Embryos were collected at E14.5 and the degree of chimerism was assessed by X-gal staining. Embryos with a high degree of chimerism presented a cleft palate (Fig. 6E). This observation could explain why ephrin-B1 ${ }^{\triangle \mathrm{PDZ}}$ male chimeras (which usually have good contribution of the mutant cells) were never recovered alive. The defect in palatal shelves formation in chimeric embryos analyzed by histology ( $n=4$, from two distinct ES clones) was very similar to the defects observed in ephrin-B1 ${ }^{\mathrm{NCC}}$ mutants. Indeed, in E14.5 chimeric embryos, palatal shelves were present but failed to elevate and fuse (Fig. 6F). This suggests that the cell-autonomous function of ephrin-B1 in NCCs is achieved through reverse signaling and interaction with key PDZ-containing proteins. No defect in body wall closure or digit formation were observed in chimeric embryos, which could indicate that reverse signaling through the PDZ-binding domain is not required in all tissues. Because these embryos are chimeric, it is also possible that contribution of wild-type cells to these tissues was sufficient to prevent defects.

\section{Discussion}

Mosaic expression of ephrin-B1 in heterozygous females correlates with polydactyly

An intriguing phenotype of the ephrin-B1 mutant mice is the polydactyly that is restricted to heterozygous females, but is never seen in homozygous null mutants. We have shown that the expression of ephrin-B1 in heterozygous females is mosaic and Compagni et al. (2003) have elegantly shown that the areas devoid of ephrin-B1 correlate with $\mathrm{X}$-inactivation of the wild-type allele. These results demonstrated that the atypical expression pattern of ephrin-B1 seen in heterozygous mutants was a consequence of random $\mathrm{X}$-inactivation. However, the size of the ephrin-B1-positive patches suggests an active process of sorting out between ephrin-B1-positive and negative cells in heterozygous female embryos. The fact that the appearance and distribution of the ephrin-B1positive patches is a function of time also argues for an active process rather than random events. This process may be dependent on Eph receptors as proposed by Compagni et al. (2003), or alternatively, ephrin-B1-positive and negative cells may exhibit a slight difference in adhesive properties that could account for the sorting out between these two populations. Ephrin-induced sorting out of mesenchymal cells has been reported very recently in the chick limb bud (Wada et al. 2003). This report showed that ectopic expression of ephrin-A2 in the limb bud led to aggregation of the overexpressing cells and was accompanied by skeletal defects including polydactyly and syndactyly, two phenotypes that we have observed in the ephrin-B1 heterozygous mutant mice.

A puzzling observation is that despite the fact that all tissues expressing ephrin-B1 are affected by the sorting out, this is of phenotypic consequences only in the limb bud. One possible explanation could be that the limb bud is the only tissue that is sensitive to differences in cell adhesion rather than defect in Eph/ephrin signaling per se. It is known that sorting out between distinct populations of mesenchymal cells occurs in the limb bud and is important for proper patterning (Yajima et al. 2002). In addition, Hoxa13, which has been implicated in polydactyly, has been shown to regulate mesenchymal cell adhesion. Indeed, in the chick limb bud, it was shown that Hoxa13-positive cells sort out from Hoxa13-negative cells, via homophilic adhesion of the Hoxa13-expressing cells (Yokouchi et al. 1995). The polydactyly phenotype does not appear to be accompanied by changes in expression of genes that lead to a similar phenotype, such as Shh and Hoxa13 (Zakani and Duboule 1999; Hill et al. 2003). This could suggest that ephrin-B1 is downstream of Hoxa13 or Shh in the cascade regulating postaxial digits formation. In support of this, it was shown previously that the expression of one member of the Eph receptor family, EphA7, was markedly reduced in Hoxa13 mutant limbs and that loss of EphA7 correlated with a loss of chondrogenic capacity (Stadler et al. 2001). As we have no evidence that the chondrogenic capacity of ephrin-B1 mutant cells is affected, it is possible that defects arise later, possibly at the step of mesenchymal condensations. The expression of ephrin-B1 suggests that it may be involved in the formation and maintenance of the perichondrium, thereby affecting cartilage formation. In their study, Compagni et al. (2003) report that ephrin-B1 is expressed in the condensing mesenchyme and cognate Eph receptors are expressed in the perichondrium. In an in vitro model of mesenchymal condensation, as well as in vivo (data not shown), we have detected ephrin-B1 in the perichondrium rather than in the condensing chondrocytes. Our results do not rule out that ectopic areas of Eph/ephrin interaction are responsible for the polydac- 
tyly, but indicate that such interactions might be restricted to the perichondrium.

\section{Ephrin-B1 acts as a receptor in NCC}

Conditional deletion of ephrin-B1 showed that it is required cell autonomously in NCCs. Although ephrins and Eph receptors have been implicated previously in NCC migration, most studies to date have demonstrated that ephrins act as repellent cues for Eph receptor expressing NCCs. For instance, it is known that in the trunk, ephrin-B1 and ephrin-B2, which are expressed in the posterior half of the somites in the chick and the mouse, respectively, restrict migration of NCCs to the anterior half of the somites (Krull et al. 1997; Wang and Anderson 1997; Santiago and Erickson 2002). Similarly, migrating cranial NCC-expressing Eph receptors are correctly targeted to their destination by ephrin-B2 expressed in the branchial arches, in a process that is independent of ephrin-B2-induced reverse signaling (Smith et al. 1997; Adams et al. 2001). Here we show that, on the contrary, ephrin-B1 acts as a receptor in NCCs, because it acts cell autonomously, and reverse signaling via its PDZ binding domain is necessary for its function. Ephrin-B1 is not required in all NCCs because trunk NCC migration did not appear affected in ephrin-B1 mutants.

Deletion of ephrin-B1 specifically in NCCs did not lead to an initial defect in the formation of the palatal shelves, as was observed in the ephrin-B1 $1^{\text {null }}$ animals. Although this may be due to incomplete recombination of the locus in the animals expressing the Wnt1-Cre transgene, this transgene has been shown to mediate efficient recombination of other loci (Tallquist and Soriano 2003). More important, the fact that heterozygous females exhibit a cleft palate with the same penetrance and the same severity as null animals supports the idea that mosaic loss of ephrin-B1 is sufficient to cause a defect in palate formation, thus indicating that incomplete deletion of ephrin-B1 in ephrin-B1 ${ }^{\mathrm{NCC}}$ animals is probably not the reason for the phenotypic difference. Instead, these results suggest a model in which ephrin-B1 would be required in two steps for palate formation. The first step, palatal shelf formation, would require ephrinB1 nonautonomously, whereas the second step, palatal shelf elevation, would require ephrin-B1 autonomously in the NCCs. The nonautonomous function of ephrin-B1 might involve delamination of a certain population of NCCs from the neural tube, as was proposed for ephrinB2 (Adams et al. 2001). Alternatively, ephrin-B1, like ephrin-B2, could be necessary in the branchial arch epithelium to guide Eph receptor-expressing NCCs (Adams et al. 2001). Consistent with the fact that ephrin-B1 acts as a receptor in NCCs, but could act as a ligand in other tissues, ephrin-B1 ${ }^{\triangle \mathrm{PDZ}}$ was capable of rescuing the formation of palatal shelves (nonautonomous first step), but could not rescue the elevation of palatal shelves (autonomous second step).

Impaired signaling through EphB2 and EphB3 receptors also leads to a cleft palate phenotype resembling that observed in ephrin-B1 ${ }^{\text {NCC }}$ but not in ephrin-B1 ${ }^{\text {null }}$ embryos (Orioli et al. 1996; Halford et al. 2000), raising the possibility that ephrin-B1 might have an Eph-receptor independent function. Candidates for Eph receptor independent pathways that could impinge on ephrin-mediated signaling are RTKs such as platelet-derived growth factor receptor (PDGFR), which are able to induce tyrosine phosphorylation of transmembrane ephrins (Bruckner et al. 1997). Preliminary data indicate that $\operatorname{PDGFR} \alpha$, which also acts cell autonomously in NCCs and is required for palate development (Tallquist and Soriano 2003), does not, however, interact genetically with ephrin-B1 (A. Davy and P. Soriano, unpubl.).

\section{Ephrin-B1 is required for NCC directional migration}

Our work suggests that the role of ephrin-B1 in NCCs is to control directional migration toward target tissues, in agreement with known functions of ephrin/Eph signaling. In the mutant embryos, NCCs exhibited a wandering behavior, which has also been reported for other mutations, in particular for Twist homozygous mutants (Soo et al. 2002). The early lethality of the homozygous Twist mutants does not permit an assessment of whether the migration defects would affect similar NCC-derived structures as ephrin-B1 mutation. However, it has been reported that heterozygous Twist mutants present craniofacial defects reminiscent of defects seen in ephrin-B1 $1^{\text {null }}$ mutants (Bourgeois et al. 1998). The migration defects observed in the ephrin-B1 ${ }^{\text {null }}$ animals do not provoke defects in formation and differentiation of cranial ganglia. Mutant embryos presented defects in nerve fasciculation and branching that might contribute to the perinatal lethality. A role in axon fasciculation has been described for EphA/ephrinA members previously (Meima et al. 1997).

What could be the molecular mechanisms by which ephrin-B1 regulates cell migration? As mentioned earlier, ephrin-B1 might function in part as a ligand to regulate NCC migration via activation of Eph receptors. Alternatively, our work demonstrates that ephrin-B1 also controls NCCs migration as a receptor, presumably by activating a signaling cascade involving a PDZ-containing protein. One candidate that might act downstream of ephrin-B1 in NCCs is the PDZ-containing protein PDZRGS3 that has been shown to be an effector of ephrin-B1 in regulating the migration of cerebellar granule cells $(\mathrm{Lu}$ et al. 2001). Preliminary data indicate that PDZ-RGS3 is indeed expressed in branchial arches (A. Davy and P. Soriano, unpubl.).

In conclusion, our work demonstrates that ephrin-B1 plays an important role in different tissues during embryogenesis and that reverse signaling is an essential component of ephrin-B1 function. As was shown for other members of the ephrin family, at the cellular level ephrin-B1 seems to regulate adhesion/migration processes. Interestingly, our results suggest that a reverse signaling cascade is required downstream of ephrin-B1 in a tissue-specific manner. Further studies will be necessary to clarify the role of ephrin-B1 in each tissue and to 
identify the specific effectors of ephrin-B1-induced reverse signaling in these tissues.

\section{Materials and methods}

\section{Generation of mutant mice}

For the conditional deletion of ephrin-B1, exons 2-5 of the efnb1 gene were flanked by loxP sites (Fig. 1). The targeting vector included two regions of homology with the genomic locus (delineated by XhoI and KpnI sites and by BglII and NheI sites). A phospho-glycerate kinase-1 (PGK)-neo-bpA cassette flanked by FRT sites was inserted at the BglII site and used for positive selection. PGK-DTA (diphtheria toxin A) was used as a negative selection cassette. For the ephrin-B1 ${ }^{\triangle \mathrm{PDZ}}$ mutation, the targeting vector was identical to the conditional "knock-out" targeting vector, except no loxP sites were introduced (Fig. 6). The mutation was introduced by PCR on a genomic DNA fragment encompassing exon 5 . The primers used for mutagenesis were as follows: 5' -CTGGGCCTTCACTTGTAGTAGATG- ${ }^{\prime}$ ' and 5'-C ATCTACTACAAGTGAAGGCCCAG-3', which deletes V345. The mutated exon 5 was subsequently cloned into the targeting vectors. The mutation-specific primer used for PCR was $5^{\prime}$-GC CATGCTGGGCCTTCACT-3'.

Targeting vectors were electroporated into AK7.1 ES cells and after positive and negative selection were applied, resistant clones were screened by Southern blot hybridization using $5^{\prime}$ and $3^{\prime}$ external probes, as well as a neomycin probe. Two correctly targeted clones for each mutation were used for injection into blastocysts and generation of chimeric mice.

\section{Genotyping of mutant mouse lines}

Mice carrying the conditional allele of $e f n b 1$ and the neomycin cassette were genotyped by PCR on tail DNA using the following primers: 5'-AGCAGTGGGGTAGTGACTACC-3', 5' -TGGCCTTACACCGCTTAAGT-3', 5'-GCTGCTAAAGCGCAT GCTCC-3' (lox, 500 bp; wt, 250 bp). Deletion of the efnb1 gene in these animals following Cre-mediated recombination was detected by PCR with the following primers: 5'-GCTGCTAAA GCGCATGCTCC-3', 5'-CCTAACCACAGATGGTGGCC-3' (del, $700 \mathrm{bp}$ ). The neomycin cassette was removed in some animals by crossing mice carrying the conditional allele of efnb1 with ROSA26 ${ }^{\text {FlpeR }}$ mice (Farley et al. 2000). These animals were genotyped by PCR using the following primers: 5 '-CCTAAC CACAGATGGTGGCC-3', 5' -TGGCCTTACACCGCTTAAG3', 5'-AGCAGTGGGGTAGTGACTACC-3' (lox, 350 bp; wt, $250 \mathrm{bp}$; del, $500 \mathrm{bp}$ ). Removal of the neomycin cDNA as well as proper recombination of the different alleles was verified by Southern blot hybridization in the first few litters. Presence of the neomycin cassette had no effect on the phenotype of either the ephrin-B1 conditional or deficient animals, as judged by skeletal, craniofacial, and body wall closure defects.

\section{Whole-mount in situ hybridization}

Embryos were fixed in $4 \%$ paraformaldehyde (PFA) overnight and subsequently dehydrated in phosphate-buffered saline Tween20 (PBT) (phosphate-buffered saline [PBS]/1\% Tween)/ methanol. Embryos were stored in $100 \%$ methanol at $4^{\circ} \mathrm{C}$ until processed for in situ hybridization as described previously (Riddle et al. 1993). Hybridization with DIG-labeled riboprobes was performed at $70^{\circ} \mathrm{C}$. DIG-labeled riboprobes were detected with an AP-conjugated anti-DIG antibody (Roche) and the BM purple (Roche) was used as a substrate for alkaline phosphatase. For ephrin-B1 mRNA detection, two different riboprobes were used with the same results. One encompassed the entire cDNA and the other one corresponded roughly to the $5^{\prime}$ half of the cDNA. At least five embryos of each genotype were analyzed for each probe.

\section{Whole-mount immunohistochemistry}

Embryos were collected and fixed in 4\% PFA overnight and dehydrated in $\mathrm{PBT} / \mathrm{methanol}$. Embryos were immediately rehydrated and incubated for 5-30 min in PBT containing 6\% $\mathrm{H}_{2} \mathrm{O}_{2}$ to inactivate endogenous peroxidases. After two washes in PBT, embryos were incubated for $1 \mathrm{~h}$ at room temperature in blocking solution (PBT/ $1 \%$ bovine serum albumin (BSA) containing $5 \%$ normal goat serum). Incubation with the primary antibody was in the blocking solution overnight at $4^{\circ} \mathrm{C}$. The EphA4 antibody was used at $1 / 200$; the neurofilament antibody $(2 \mathrm{H} 3$, Developmental Studies Hybridoma Bank at the University of Iowa) was used at 1/50. Embryos were washed with frequent changes of Tris-buffered saline (TBS) and blocked as described earlier prior to overnight incubation with a horseradish peroxidase (HRP)-conjugated secondary antibody. The next day, embryos were washed for at least $4 \mathrm{~h}$ with frequent changes of TBS prior to 3-3' diaminobenzidine (DAB) staining (Vector Laboratories Inc.).

\section{Skeletal preparations}

E18.5 or P1 animals were skinned, eviscerated, and fixed in $95 \%$ ethanol overnight. Skeletons were then stained with Alcian blue solution (15\% Alcian blue 8GX, 20\% acetic acid in 95\% ethanol) overnight at $37^{\circ} \mathrm{C}$. Skeletons were rinsed extensively in $95 \%$ ethanol over a $24-\mathrm{h}$ period. After clearing in $1 \% \mathrm{KOH}$ for 2 $\mathrm{h}$, skeletons were transferred to an Alizarin red solution $15 \%$ Alizarin red in $2 \% \mathrm{KOH}$ ) for $3 \mathrm{~h}$. Skeletons were then rinsed and cleared in $1 \% \mathrm{KOH}$. Cleared skeletons were stored in $50 \%$ ethanol $/ 50 \%$ glycerol.

\section{Western blot}

E10.5 embryos were lysed in 1\% NP40 lysis buffer $(50 \mathrm{mM}$ Hepes at pH 7.5, $150 \mathrm{mM} \mathrm{NaCl}, 10 \%$ glycerol, $1.5 \mathrm{mM} \mathrm{MgCl}_{2}$, $1 \mathrm{mM}$ EGTA, $100 \mathrm{mM} \mathrm{NaF}$ ) containing $1 \mathrm{mM}$ PMSF, $1 \mathrm{mM}$ sodium orthovanadate, and $10 \mu \mathrm{g} / \mathrm{mL}$ aprotinin. Cell lysates were incubated on ice for at least $15 \mathrm{~min}$ and centrifuged $10 \mathrm{~min}$ at $8000 \mathrm{rpm}$. Protein content of each lysate was quantified with a Bio-Rad DC Protein Assay kit (BCA) protein quantification kit (Bio-Rad) and $50 \mu \mathrm{g}$ protein was loaded on an SDS-PAGE. Proteins were transferred onto a polyvinylidene fluoride (PVDF) membrane using the standard wet-transfer method. Incubation with primary antibodies was performed overnight at $4^{\circ} \mathrm{C}$ using the appropriate antibody dilution. The following antibodies were used: anti-P-Tyr (4G10) from UBI and anti-ephrin (C18) from Santa Cruz.

For ES cell Western blot experiments, ES cells were grown onto gelatinized dishes in the absence of feeder cells and treated with $1 \mu \mathrm{M}$ RA for 24 or $48 \mathrm{~h}$. Cells were lysed in $1 \%$ NP40 lysis buffer and processed for Western blot analysis as described earlier.

HEK 293T cells were cotransfected with $0.5 \mu$ g ephrin-B2 expression vector and $0.5 \mu \mathrm{g}$ PDZ-flag (pFlag in which PDZ domains of glutamate receptor interacting protein (GRIP) have been fused in frame with flag), using the calcium/phosphate method. Forty-eight hours after transfection, cells were incubated with $2 \mu \mathrm{g} / \mathrm{mL}$ EphB2-Fc recombinant protein (R\&D systems) for $30 \mathrm{~min}$ at $37^{\circ} \mathrm{C}$ prior to lysis. Cell lysates were then incubated with Protein A-Sepharose for $45 \mathrm{~min}$ at $4^{\circ} \mathrm{C}$ and protein complexes were analyzed on Western blot using the M2 anti-Flag antibody (Sigma) and the anti-ephrin (C18) antibody. 


\section{Immunofluorescence on cells isolated from branchial arches}

Cells were dissociated from branchial arches isolated from E10.5-E11.5 embryos using a 1\% trypsin/0.1\% DNase solution. Dissociated cells were plated on a poly-L-lysine-coated glass coverslip and grown overnight in Dulbecco's Minimal Eagle Medium (DMEM) containing 10\% fetal calf serum (FCS). Cells were fixed in $2 \%$ PFA and incubated with anti-ephrin-B1 antibody (25H11) or ephrin-B1-Fc (R\&D systems). Eph/ephrin complexes were detected using an fluorescein isothiocyanate (FITC)-conjugated anti-human antibody (Jackson Immunoresearch).

\section{Micromass cultures of embryonic limb buds}

Limb buds from E11.5 embryos were dissected in PBS and incubated for $10 \mathrm{~min}$ in $1 \%$ trypsin $/ 0.1 \%$ DNase at $37^{\circ} \mathrm{C}$. Limb buds from individual embryos were processed separately. Tissues were broken up during the course of the incubation by repeated pipetting. Trypsin was inactivated at the end of the incubation by adding one volume of DMEM containing 10\% FCS. Cells were then dissociated by repeated pipetting in a Pasteur pipette. Dissociated cells were washed twice in DMEM/ $10 \%$ FCS and resuspended in $50 \mu \mathrm{L}$ DMEM/10\% FCS. Twenty microliters of the cell suspension was plated in one drop at the center of a poly-L-lysine-coated glass coverslip. Cells were allowed to attach for $1 \mathrm{~h}$ at $37^{\circ} \mathrm{C}$ before the well was flooded with DMEM $/ 10 \%$ FCS. Cells were grown for $4 \mathrm{~d}$ with daily change of culture medium. On the fourth day, cells were fixed in $2 \%$ PFA for $10 \mathrm{~min}$ at room temperature and permeabilized in $0.1 \%$ TX-100. Cells were then incubated for $1 \mathrm{~h}$ at room temperature with primary antibodies diluted in $\mathrm{PBS} / 1 \% \mathrm{BSA}$. The antiEphA4 antibody was used at 1/500, the anti-ephrin-B1 (25H11) was used at $1 / 20$, and the anti-collagenII antibody (Developmental Studies Hybridoma Bank, University of Iowa) was used at $1 / 100$. After three washes in PBS, cells were incubated with appropriate fluorescent secondary antibodies (Molecular Probes and Jackson Immunoresearch).

\section{Acknowledgments}

We thank David Wilkinson for providing us with the antiEphA4 polyclonal antibody and Wieland Huttner for sharing the ephrin-B1-specific monoclonal antibody (25H11). The Wnt1Cre mice were kindly provided by Andy McMahon. We obtained the PDZ-flag expression vector from Dan Lin. We are grateful to Philip Corrin and Jason Frazier for excellent technical assistance, and to Cecilia Moens, Valera Vasioukhin, and our laboratory colleagues for critical comments on the manuscript. A.D. and J.A were the recipients of fellowships from the Human Frontier Science Program long-term and the Canadian Institutes of Health Research, respectively. This work was supported by grants HD24875 and HD 25326 from the National Institutes of Child Health and Human Development to P.S.

The publication costs of this article were defrayed in part by payment of page charges. This article must therefore be hereby marked "advertisement" in accordance with 18 USC section 1734 solely to indicate this fact.

\section{References}

Adams, R.H. 2002. Vascular patterning by Eph receptor tyrosine kinases and ephrins. Semin. Cell Dev. Biol. 13: 55-60.

Adams, R.H., Diella, F., Hennig, S., Helmbacher, F., Deutsch, U., and Klein, R. 2001. The cytoplasmic domain of the ligand
ephrinB2 is required for vascular morphogenesis but not cranial neural crest migration. Cell 104: 57-69.

Bouillet, P., Oulad-Abdelghani, M., Vacaire, S., Garnier, J.M., Schuhbaur, B., Dolle, P., and Chambon, P. 1995. Efficient cloning of cDNAs of retinoic acid-responsive genes in P19 embryonal carcinoma cells and characterization of a novel mouse gene, Stral (mouse LERK-2/Eplg2). Dev. Biol. 170: 420-433.

Bourgeois, P., Bolcato-Bellemin, A.-L., Danse, J.-M., BlochZupan, A., Yoshiba, K., Stoetzel, C., and Perrin-Schmitt, F. 1998. The variable expressivity and incomplete penetrance of the twist-null heterozygous mouse phenotype resemble those of human Saethre-Chotzen syndrome. Hum. Mol. Genet. 7: 945-957.

Bruckner, K., Pasquale, E.B., and Klein, R. 1997. Tyrosine phosphorylation of transmembrane ligands for Eph receptors. Science 275: 1640-1643.

Compagni, A., Logan, M., Klein, R., and Adams, R.H. 2003. Control of skeletal patterning by ephrinB1-EphB interactions. Dev. Cell 5: 217-230.

Cowan, C.A. and Henkemeyer, M. 2001. The SH2/SH3 adaptor Grb4 transduces B-ephrin reverse signals. Nature 413: 174 179.

Danielian, P.S., Muccino, D., Rowitch, D.H., Michael, S.K., and McMahon, A.P. 1998. Modification of gene activity in mouse embryos in utero by a tamoxifen-inducible form of Cre recombinase. Curr. Biol. 8: 1323-1326.

Davy, A., Gale, N.W., Murray, E.W., Feuerstein, C., Klinghoffer, R., Soriano, P., and Robbins, S.M. 1999. Compartmentalized signaling by GPI-anchored Ephrin-A5 requires the Fyn tyrosine kinase to regulate cellular adhesion. Genes \& Dev. 13: $3125-3135$.

Drescher, U. 1997. The Eph family in the patterning of neural development. Curr. Biol. 7: R799-R807.

Farley, F.W., Soriano, P., Steffen, L.S., and Dymecki, S.M. 2000. Widespread recombinase expression using FLPeR (flipper) mice. Genesis 28: 106-110.

Fletcher, F.A., Carpenter, M., Shilling, H., Baum, P., Ziegler, S., Gimpel, S., Hollingsworth, T., Vanden Bos, T., Davison, B.L., Lyman, S.D., et al. 1994. LERK-2, a binding protein for the receptor-tyrosine kinase ELK, is evolutionarily conserved and expressed in a developmentally regulated pattern. Oncogene 9: 3241-3247.

Halford, M.M., Armes, J., Buchert, M., Meskenaite, V., Grail, D., Hibbs, M.L., Wilks, A.F., Farlie, P.G., Newgreen, D.F., Hovens, C.M., et al. 2000. Ryk-deficient mice exhibit craniofacial defects associated with perturbed Eph receptor crosstalk. Nature 25: 414-418.

Henkemeyer, M., Orioli, D., Henderson, J.T., Saxton, T.M., Roder, J., Pawson, T., and Klein, R. 1996. Nuk controls pathfinding of commissural axons in the mammalian central nervous system. Cell 86: 35-46.

Hill, R.E., Heaney, S.J., and Lettice, L.A. 2003. Sonic Hedgehog: Restricted expression and limb dysmorphologies. J. Anat. 202: $13-20$.

Holland, S.J., Gale, N.W., Mbamalu, G., Yancopoulos, G.D., Henkemeyer, M., and Pawson, T. 1996. Bidirectional signalling through the EPH-family receptor Nuk and its transmembrane ligands. Nature 383: 722-725.

Huai, J. and Drescher, U. 2001. An ephrin-A-dependent signaling pathway controls integrin function and is linked to the tyrosine phosphorylation of a $120-\mathrm{kDa}$ protein. J. Biol. Chem. 276: 6689-6694.

Kalo, M.S., Yu, H.-H., and Pasquale, E.B. 2001. In vivo tyrosine phosphorylation sites of activated ephrin-B1 and EphB2 from neural tissue. J. Biol. Chem. 276: 38940-38948. 
Krull, C.E., Lansford, R., Gale, N.W., Collazo, A., Marcelle, C., Yancopoulos, G.D., Fraser, S.E., and Bronner-Fraser, M. 1997. Interactions of Eph-related receptors and ligands confer rostrocaudal pattern to trunk neural crest migration. Curr. Biology 7: 571-580.

Lin, D., Gish, G.D., Songyang, Z., and Pawson, T. 1999. The carboxy terminus of $\mathrm{B}$ class ephrins constitutes a PDZ domain binding motif. J. Biol. Chem. 274: 3726-3733.

Lu, Q., Sun, E., Klein, R., and Flanagan, J. 2001. Ephrin-B reverse signaling is mediated by a novel PDZ-RGS protein and selectively inhibits G-protein-coupled chemoattraction. Cell 105: 69-79.

Meima, L., Klavin, I.J., Moran, P., Shih, A., Winslow, J.W., and Caras, I.W. 1997. AL-1-induced growth cone collapse of rat cortical neurons is correlated with REK7 expression and rearrangement of the actin cytoskeleton. Eur. I. Neurosci. 9: $177-188$.

Mellitzer, G., Xu, Q., and Wilkinson, D.G. 1999. Eph receptors and ephrins restrict cell intermingling and communication. Nature 400: 77-81.

Mori-Akiyama, Y., Akiyama, H., Rowitch, D.H., and de Combrugghe, B. 2003. Sox 9 is required for determination of the chondrogenic cell lineage in the cranial neural crest. Proc. Natl. Acad. Sci. 100: 9360-9365.

Orioli, D., Henkemeyer, M., Lemke, G., Klein, R., and Pawson, T. 1996. Sek4 and Nuk receptors cooperate in guidance of commissural axons and in palate formation. EMBO $J$. 15: 6035-6049.

Palmer, A. and Klein, R. 2003. Multiple roles of ephrins in morphogenesis, neuronal networking, and brain function. Genes \& Dev. 17: 1429-1450.

Palmer, A., Zimmer, M., Erdmann, K.S., Eulenburg, V., Parthin, A., Heumann, R., Deutsch, U., and Klein, R. 2002. EphrinB phosphorylation and reverse signaling: Regulation by Src kinases and PTP-BL phosphatase. Mol. Cell 9: 725-737.

Patel, K., Nittenberg, R., D'Souza, D., Irving, C., Burt, D., Wilkinson, D.G., and Tickle, C. 1996. Expression and regulation of cek-8, a cell to cell signalling receptor in developing chick limb buds. Development 122: 1147-1155.

Riddle, R.D., Johnson, R.L., Laufer, E., and Tabin, C. 1993. Sonic hedgehog mediates polarizing activity of the ZPA. Cell 75: 1401-1416.

Santiago, A. and Erickson, C.A. 2002. Ephrin-B ligands play a dual role in the control of neural crest cell migration. Development 129: 3621-3632.

Smith, A., Robinson, V., Patel, K., and Wilkinson, D.G. 1997. The EphA4 and EphB1 receptor tyrosine kinases and ephrinB2 ligand regulate targeted migration of branchial neural crest cells. Curr. Biology 7: 561-570.

Soo, K., O'Rourke, M.P., Khoo, P.-L., Steiner, K.A., Wong, N., Behringer, R.R., and Tam, P.P.L. 2002. Twist function is required for the morphogenesis of the cephalic neural tube and the differentiation of the cranial neural crest cells in the mouse embryo. Dev. Biol. 247: 251-270.

Soriano, P. 1999. Generalized lacZ expression with the ROSA26 Cre reporter strain. Nat. Genet. 21: 70-71.

Spokony, R.F., Aoki, Y., Saint-Germain, N., Magner-Fink, E., and Saint-Jeannet, J.-P. 2002. The transcription factor Sox9 is required for cranial neural crest development in Xenopus. Development 129: 421-432.

Stadler, H.S., Higgins, K.M., and Capecchi, M.R. 2001. Loss of Eph-receptor expression correlates with loss of cell adhesion and chondrogenic capacity in Hoxa13 mutant limbs. Development 128: 4177-4188.

Tallquist, M.D. and Soriano, P. 2000. Epiblast-restricted Cre expression in MORE mice: A tool to distinguish embryonic vs. extra-embryonic gene function. Genesis 26: 113-115 2003. Cell autonomous requirement for PDGFRalpha in populations of cranial and cardiac neural crest cells. Development 130: 507-518.

Torres, R., Firestein, B.L., Dong, H., Staudinger, J., Olson, E.N., Huganir, R.L., Bredt, D.S., Gale, N.W., and Yancopoulos, G.D. 1998. PDZ proteins bind, cluster, and synaptically colocalize with Eph receptors and their ephrin ligands. Neuron 21: 1453-1463.

Wada, N., Tanaka, H., Ide, H., and Nohno, T. 2003. Ephrin-A2 regulates position-specific cell affinity and is involved in cartilage morphogenesis in the chick limb bud. Dev. Biol. 264: 550-563.

Wang, H.U. and Anderson, D.J. 1997. Eph family transmembrane ligands can mediate repulsive guidance of trunk neural crest migration and motor axon outgrowth. Neuron 18: 383396.

Wilkinson, D.G. 2001. Multiple roles of Eph receptors and ephrins in neural development. Nat. Rev. Neurosci. 2: 155-164.

Yajima, H., Hara, K., Ide, H., and Tamura, K. 2002. Cell adhesiveness and affinity for limb pattern formation. Int. J. Dev. Biol. 46: 897-904.

Yokouchi, Y., Nakazato, S., Yamamoto, M., Goto, Y., Kameda, T., Iba, H., and Kuroiwa, A. 1995. Misexpression of Hoxa-13 induces cartilage homeotic transformation and changes cell adhesiveness in chick limb buds. Genes \& Dev. 15: 25092522.

Yokoyama, N., Romero, M.I., Cowan, C.A., Galvan, P., Helmbacher, F., Charnay, P., Parada, L.F., and Henkemeyer, M. 2001. Forward signaling mediated by ephrin-B3 prevents contralateral corticospinal axons from recrossing the spinal cord midline. Neuron 29: 85-97.

Zakani, J. and Duboule, D. 1999. Hox genes in digit development and evolution. Cell Tissue Res. 296: 19-25.

Zambrowicz, B.P., Imamoto, A., Fiering, S., Herzenberg, L.A., Kerr, W.G., and Soriano, P. 1997. Disruption of overlapping transcripts in the ROSA beta geo 26 gene trap strain leads to widespread expression of beta-galactosidase in mouse embryos and hematopoietic cells. Proc. Natl. Acad. Sci. 15: 3789-3794.

Zimmer, M., Palmer, A., Kohler, J., and Klein, R. 2003. EphBephrinB bi-directional endocytosis terminates adhesion allowing contact mediated repulsion. Nat. Cell Biol. 5: 869878. 


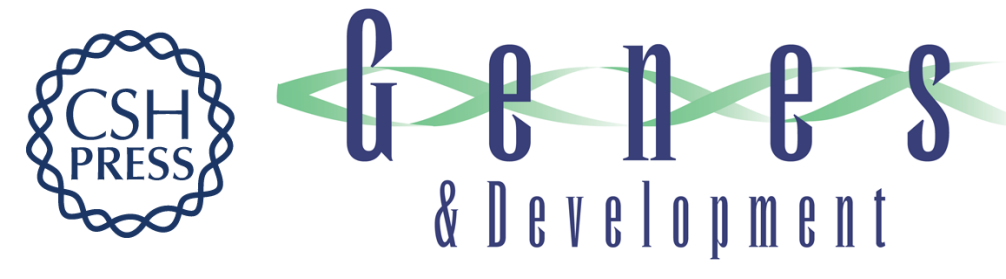

\section{Ephrin-B1 forward and reverse signaling are required during mouse development}

Alice Davy, Josée Aubin and Philippe Soriano

Genes Dev. 2004, 18:

Access the most recent version at doi:10.1101/gad.1171704

References This article cites 44 articles, 11 of which can be accessed free at: http://genesdev.cshlp.org/content/18/5/572.full.htmI\#ref-list-1

License

Email Alerting Receive free email alerts when new articles cite this article - sign up in the box at the top Service right corner of the article or click here.

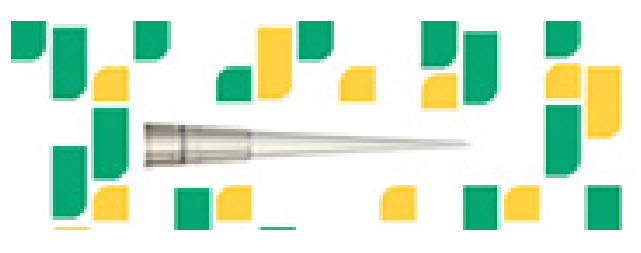

Focused on your science. 